\title{
Food intake survey of kindergarten children in Korea: Part 2 increased dietary intake of tin possibly associated with canned foods
}

\author{
Hye-Ran Yang ${ }^{1}$ Eul-Sang Kim ${ }^{2} \cdot$ Yang-Sook Ko $^{3} \cdot \mathrm{Kweon} \mathrm{Jung}^{1} \cdot$ \\ Jung-Hun Kim ${ }^{1}$. Takao Watanabe ${ }^{4} \cdot$ Haruo Nakatsuka ${ }^{5}$ Chan-Seok Moon ${ }^{6}$. \\ Shinichiro Shimbo ${ }^{7} \cdot$ Masayuki Ikeda $^{8}$
}

Received: 17 March 2015/Accepted: 13 April 2015/Published online: 21 May 2015

(C) The Japanese Society for Hygiene 2015

\begin{abstract}
Objectives Dietary intake of tin ( $\mathrm{Sn})$ may be increased in some children in kindergartens in Korea. The present study was intended to examine this possibility and clarify the extent of the elevation.

Methods 24-hour food duplicate and spot urine samples were collected in 2003-2004 from 108 4-6-year-old children (boys and girls combined) in 4 kindergartens ( 1 in Seoul and 3 in Jeju Island), as reported in a previous publication. These samples were employed in the present analyses to examine tin levels in the diet (including beverages) (Sn-D). A portion of the samples were wet-ashed, and the liquid samples were analyzed for Sn by the ICP-
\end{abstract}

\section{E.-S. Kim: Deceased.}

Masayuki Ikeda

m-71-ikeda@nifty.com

1 Seoul Metropolitan Government Research Institute of Public Health and Environment, Seoul 137-734, Korea

2 Department of Food and Nutrition, Dankook University, Yongin 448-701, Gyeonggi, Korea

3 Department of Food and Nutrition, Jeju National University, Jeju 690-756, Korea

4 Department of Childhood Education, Faculty of Human Sciences, Tohoku Bunkyo University, Yamagata 990-2316, Japan

5 School of Nursing, Miyagi University, Taiwa-cho 981-3298, Japan

6 Department of Industrial Health, Catholic University of Pusan, Busan 609-757, Korea

7 Kyoto Women's University, Kyoto 605-8501, Japan

8 Kyoto Industrial Health Association, Kyoto 604-8472, Japan
MS method. For statistical evaluation, $\chi^{2}$ method and Smirnov's test for extreme value were used.

Results Sn-D in the 108 cases distributed as extremely biased, and could be divided into two groups, i.e., those with $<10 \mu \mathrm{g} \mathrm{Sn} /$ day (accounting for $90 \%$ of the cases), and those with $>10 \mu \mathrm{g} /$ day (for $10 \%$ ). Sn-D in the former group was distributed quasi-normally with an AM (median) of 2.9 (2.5) $\mu \mathrm{g} / \mathrm{day}$. The maximum in the latter group was $3012 \mu \mathrm{g} /$ day. No correlation was detected between Sn-D and $\mathrm{Sn}$ in urine (Sn-U). Comparison of the findings with published articles strongly suggested that the high Sn-D was due to consumption of foods (including beverages) preserved in tin-plated cans. No positive confirmation was however possible due to insufficient information on food records.

Conclusions About $10 \%$ of children surveyed had elevated Sn-D (up to $3 \mathrm{mg} /$ day). It was quite possible that high Sn-D was associated with tin-canned food intake.

Keywords Canned foods $\cdot$ Children · Dietary intake · Korea · Tin

\section{Introduction}

Tin (Sn) is an element with low toxicity, unique in the sense that this element has a direct contact with daily foods, typically through contact with canned foods. Examples are fruits (canned peach and pineapple), fish (canned tuna and salmon) and some types of beverages. The contact is due to the fact that metallic tin has been employed to cover inner surface of food-preserving can materials [1]. Sn may be dissolved into liquid portion in the can, and then to food materials [1]. Thus, consumption of foods and drinks in tin-plated cans may result in elevated oral intake of inorganic tin. 
Such possibilities have not been examined in Asia except for Shimbo et al. [2, 3] in Japan. The present study was initiated to examine if such is also the case in Korea, and if so, to what extent.

Another application of tin as a matter of social concern has been the use of organotin compounds (typically tributyltin, tributyltin oxide and triphenyltin) as an antifoulant and an molluscicide which induced pollution of water including oceans $[4,5]$. The risk of direct exposure to organotin compounds was considered to be remote [4, 5] and was not taken into consideration in this study.

\section{Materials and methods}

\section{Survey sites, participating children and sample collection}

Survey sites and demographic characteristics of participating children were detailed in a preceding article [6]. In short, the surveys were conducted in 1 kindergarten (KG 1 with 33 attending children) in Seoul in September, 2004, and in 3 KGs in Jeju Island in October, 2003 (KG 2 in the city of Jeju with 37 attending children, KG 3 with 18 children and KG 4 with 20 children in rural villages in the island). In total, 108 children (boys and girls combined) at the ages of 4-6 years participated in the study. Both 24-h food duplicate samples and morning spot urine samples were collected. Guardians of the children (mostly mothers) provided informed consents. The study protocol was approved by the Institutional Review Board of Dankook University (DKU2015-03-006), Yongin-si, Gyeonggi-do 448-701, Korea.

\section{Instrumental analysis for Sn}

Preparation of the wet-ashed samples was as previously described [2, 3]. Sn concentrations in the liquid samples were measured by the ICP-MS method essentially as previously described $[2,3]$. The samples from KG 1 in Seoul were in the analytical laboratory in Shimadzu Techno-research, Inc., Kyoto, Japan, whereas the samples from KGs 2, 3 and 4 in Jeju Island were analyzed in Kyoto Women's University [3]. The performances of both laboratories were sufficient. The quality of the analysis in the former laboratory was approved by International Organization for Standardization (ISO) 17025. The excellent performance in the latter laboratory was previously reported [2, 3]. Thus, the analysis results from two laboratories were considered to be compatible to each other. The quantification limits (QLs) [7] were 0.05 and $0.01 \mathrm{ng} / \mathrm{g}$ sample in the former and latter laboratories, respectively, or about $0.02-0.1 \mu \mathrm{g} / \mathrm{day}$.

\section{Statistical analysis}

Distribution of Sn-D values was extremely biased, i.e., a majority was at low concentrations whereas the concentrations in a few samples were quite high (for details, see Table 1; Fig. 1). The possibility that these high Sn-D cases did not belong to the group of other low-level samples were examined by Smirnov's test for extreme values (with $p<0.01$ ).

Correlation analysis (including Spearman's analysis by ranks), and simple and multiple regression analyses were applied.

\section{Results}

\section{Biased distribution of Sn-D}

Examination for Sn-D distribution showed that, whereas the $\mathrm{Sn}$-D levels were low (i.e., $<10 \mu \mathrm{g} /$ day) in a majority of

Table 1 Distribution of Sn-D by Sn-D level

\begin{tabular}{llll}
\hline Parameters & Total & \multicolumn{2}{l}{ By Sn-D level } \\
\cline { 2 - 4 } & & $<10 \mu \mathrm{g} /$ day & $\geqq 10 \mu \mathrm{g} / \mathrm{day}$ \\
\hline No. of cases & 108 & 97 & 11 \\
Sn-D intake ( $\mu \mathrm{g} / \mathrm{day})$ & & & \\
Arithmetic mean & 37 & 2.9 & 332 \\
Arithmetic standard deviation & 291 & 1.7 & 895 \\
Geometric mean & 3.1 & 2.3 & 44 \\
Geometric standard deviation & 4.0 & 2.6 & 6.1 \\
Median & 3.0 & 2.6 & 18 \\
Minimum & $<\mathrm{QL}$ & $<\mathrm{QL}$ & 10 \\
Maximum & 3012 & 8.6 & 3012 \\
\hline
\end{tabular}

For details, see the "Materials and Methods"

$Q L$ quantification limit (=about $0.02-0.1 \mu \mathrm{g} /$ day)

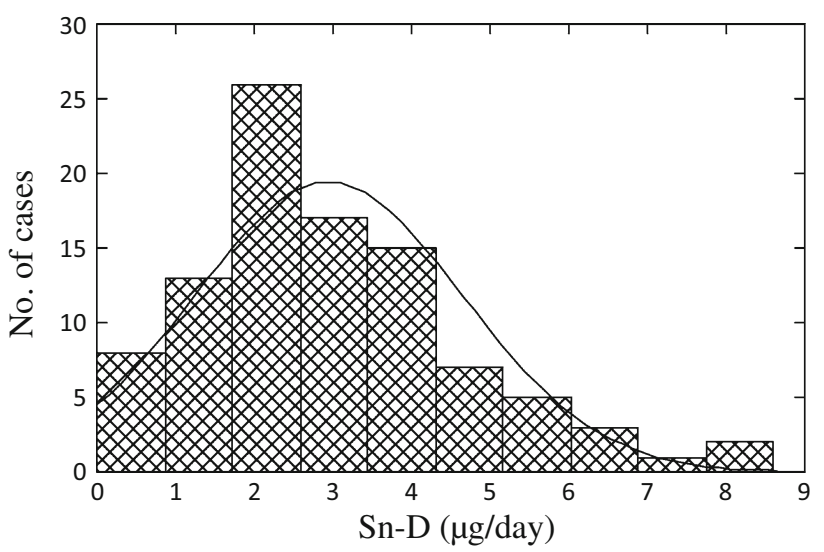

Fig. 1 Quasi-normal distribution of Sn-D in 97 cases for which Sn-D was $<10 \mu \mathrm{g} /$ day. The curve in the figure shows a normal distribution 
cases (i.e., 97 cases or $90 \%$ ), there was a few cases (i.e., 11 cases or $10 \%$ ) with substantially high Sn-D (i.e., $\gg 10 \mu \mathrm{g} /$ day). Further distribution analyses revealed that the cases with $<10 \mu \mathrm{g} /$ day were distributed quasi-normally (Fig. 1). The application of Smirnov's test for extreme values disclosed that 11 cases with $\mathrm{Sn}-\mathrm{D}>10 \mu \mathrm{g} /$ day did not belong to the group of $\mathrm{Sn}-\mathrm{D}<10 \mu \mathrm{g} / \mathrm{day}$ cases $(p<0.01)$. In other words, Sn intake of these 11 cases was substantially larger than other 97 cases.

Results of statistical analyses after subgrouping of the total 108 cases into those with Sn-D $<10 \mu \mathrm{g} /$ day and those with Sn-D $\geqq 10 \mu \mathrm{g} /$ day are summarized in Table 1 . It was clear that the distribution in the former group was essentially normal with arithmetic mean (AM) of $2.9 \mu \mathrm{g} /$ day. Geometric mean $(\mathrm{GM})$ was $2.3 \mu \mathrm{g} / \mathrm{day}$, and the median was $2.6 \mu \mathrm{g} / \mathrm{day}$. The coefficient of variation [=ASD (arithmetic standard deviation)/AM] was $59 \%$. In a sharp contrast, the distribution of $\mathrm{Sn}-\mathrm{D}$ in the latter group was extremely biased with the maximum of $>3000 \mu \mathrm{g} /$ day. Both ASD (395 $\mu \mathrm{g} /$ day) and geometric standard deviation (GSD) (6.12) were quite large.

\section{Analysis of Sn-D for possible causative foods to increase $\mathrm{Sn}-\mathrm{D}$}

The Sn-D was subjected to multiple regression analysis for possible causative food groups. In the analysis, Sn-D was taken as a dependent variable. Taking observation in food consumption by the children in the present study and findings by Shimbo et al. [3] into consideration, four food groups were selected for the analyses, i.e., Group 8 Fruits, Group 9 Meats, Group 11 Fishes and shellfishes, and Group 15 Beverages. Group 1 Cereals was also enlisted because cereals, typically boiled rice, are staple foods in Korea. Total food weight and energy were taken up according to the results by Shimbo et al. [3] as factors influential to Sn-D.

The analysis (Table 2) showed that Group 8 Fruits was the only independent variable that had a significant

Table 2 Multiple regression analysis to find food groups influentia to Sn-D

\begin{tabular}{lcl}
\hline Independent variable & SCC & $p^{\mathrm{a}}$ \\
\hline Total food weight & 0.014 & $\mathrm{~ns}$ \\
Energy intake & -0.088 & $\mathrm{~ns}$ \\
Group 1 cereals & 0.121 & $\mathrm{~ns}$ \\
Group 8 fruits & 0.228 & $<0.05$ \\
Group 9 meats & 0.162 & $\mathrm{~ns}$ \\
Group 11 fishes and shellfishes & 0.070 & $\mathrm{~ns}$ \\
Group 15 beverages & -0.018 & $\mathrm{~ns}$ \\
\hline
\end{tabular}

Units were in g/day except for energy for which was in kcal/day

$S C C$ standardized correlation coefficients

${ }^{\text {a }}$ ns: $p>0.10$ influence on Sn-D. Because the distribution of Sn-D was remarkably shewed, the association was further confirmed by non-parametric method. Spearman's correlation analysis by ranks also suggested a possible correlation $(p=0.091)$.

\section{Lack of correlation of $\mathrm{Sn}$ in urine (Sn-U) with $\mathrm{Sn}$ in daily diet (Sn-D)}

Possible correlation was examined between Sn-D and SnU. The analyses were conducted with a total of 108 cases, and also after division into two groups of Sn$\mathrm{D}<10 \mu \mathrm{g} /$ day and $\geqq 10 \mu \mathrm{g} /$ day (Table 3 ).

In the total group, the correlation coefficients were all $<0$ to indicate that the slopes of regression lines were negative. These coefficient values were statistically insignificant $(p>0.05)$. For the $\mathrm{Sn}-\mathrm{D}<10 \mu \mathrm{g} /$ day group, the coefficients were all statistically insignificant. In the $\geqq 10 \mu \mathrm{g} /$ day group, the coefficients were significant $(p<0.01)$ but they were all negative.

Thus, none of Sn-U (with or without correction for urine density) correlated with Sn-D, both in the low and high Sn$\mathrm{D}$ groups as well as in the total group.

\section{Discussion}

In 2003, Bluden and Wallace [1] published a review on contribution of tin-plating on tin levels in foods preserved in cans. Tin plated on the inside surface of can wall will migrate from the wall to liquid in the can and move into preserved food materials, and finally to meals. The same may be the case of canned beverages, especially when the liquid inside is acidic. Efforts have been made to prevent the migration, for example, by lacquering of the inside wall [1]. Blunden and Wallace [1] did not find clinical reports on chronic toxicity of inorganic tin, although tin at high concentrations may cause acute effects on the stomach [4, $5,8]$.

Only a few reports are available recently on tin migration. Thus, Kassouf et al. [9] observed no migration of tin

Table 3 Lack of correlation of Sn-U with Sn-D

\begin{tabular}{llll}
\hline Sn-U & Total & \multicolumn{2}{l}{ Group by Sn-D } \\
\cline { 3 - 4 } & & $<10 \mu \mathrm{g} /$ day & $\geqq 10 \mu \mathrm{g} /$ day \\
\hline No. of cases & 108 & 97 & 11 \\
Sn- $\mathrm{U}_{\mathrm{ob}}$ & -0.054 & 0.01 & -0.361 \\
Sn-U $_{\mathrm{cr}}$ & -0.072 & -0.04 & -0.452 \\
Sn- & -0.083 & -0.05 & -0.462 \\
\hline
\end{tabular}

Correlation coefficients were calculated taking Sn-D as an independent variable and $\mathrm{Sn}-\mathrm{U}$ as a dependent variable 
to chickpea in tin-plated cans, and Olmedo et al. [10] did not find transfer of tin from tin-plated can to fish and shellfish in the can at significant levels. In contrast, Boutakhrit et al. [11] detected tin at substantial concentrations $(41-148 \mathrm{mg} / \mathrm{kg}$ ) in various fruits in tin cans (e.g., mango slices, fruit cocktail and pineapple slices) although it was at $<2 \mathrm{mg} / \mathrm{kg}$ level in tin-canned vegetables, meat, fish, dairy products (e.g., concentrated milk), beverages and juices. No reports are available in East-Asia except for Shimbo et al. [2, 3]. In both studies on Japanese adult population [2] and on Japanese preschool children [3], the food duplicate collection method [12] was employed, followed by the ICP-MS analysis. The validity of the method for metal analyses was previously established [13].

Information on canned food consumption was also available. Shimbo et al. [3] observed that the distribution of Sn-D was extremely skewed, and that it was possible to separate the cases into two groups. In case of preschoolers who did not consume canned foods (including canned drinks) on the survey day, Sn-D distributed normally with $\mathrm{AM}$ and median of 2.9 and $2.5 \mu \mathrm{g} /$ day, respectively. The distribution of Sn-D in the canned food-consuming children was not only quite high, but biased and irregular in the distribution, i.e., the median was $10.6 \mu \mathrm{g} / \mathrm{day}$, but the maximum was as high as $3255 \mu \mathrm{g} /$ day, although no health effects were observed. It may be interesting to note that both AMs and the median values were quite close to each other between the canned food non-consumers in the Shimbo et al. [3] study and the children in the present study with Sn-D $<10 \mu \mathrm{g} /$ day.

The comparison of the distribution patterns observed in the present study (Table 1; Fig. 1) with that of Shimbo et al. [3] disclosed a clear similarity, and the possibility was strongly suggested that the high Sn-D observed in the present study may be associated with the consumption of canned foods (including canned soft drinks). The observation in daily life of children suggested that fish and shellfish, meat (mostly beef), fruits (such as pineapple, peach, and tangerine) as canned were often served, and children liked to drink canned beverages [3]. Based on the observation, possible association was examined for Sn-D ( $\mu \mathrm{g} /$ day) and consumed amounts of foods and beverages in food groups of fruit, meat, fish and beverages. The association was suggested only for fruit intake, but failed to suggest positive association for other food groups, possibly because the food groups include many non-canned food items.

Although the statistical power for contribution of fruits was weak, this observation in combination with negative findings on other foods may be taken as what is on line with the results by Bautakhrit et al. [11] in the sense to suggest that canned fruits are most possible source of tin in meals.
There may be several limitations in the present study. One is that analysis for Sn was conducted in two analytical laboratories. Although quality assurance information suggested that the results from the two laboratories were compatible, it was certainly desirable to complete all analyses in a single laboratory to avoid any inter-laboratory difference. The second issue should be the limited availability of information on canned food consumption. The insufficiency made it difficult to conduct detailed analysis for possible association between elevated Sn-D and canned food consumption other than the analysis on a food group basis.

To conclude, the present survey made it clear that Sn-D was low $(<10 \mu \mathrm{g} /$ day $)$ in a majority of children, but extremely high (up to $>3000 \mu \mathrm{g} / \mathrm{day}$ ) in a small number of children. Possible association of high Sn-D with consumption of canned foods was suspected but no positive confirmation was possible due to limitation in information availability. The study dealt with children and no survey was conducted on Sn-D for adult populations. According to the study by Shimbo et al. [2,3] which was conducted in Japan, median Sn-D for adults (ca. $0.6 \mu \mathrm{g} / \mathrm{kg}$ body weight/day) appeared to be greater than the value for children (ca. $0.3 \mu \mathrm{g} / \mathrm{kg} / \mathrm{day}$ ), but the difference was statistically insignificant due to wide inter-individual variation as observed in the present study.

Trials in the present study to biomonitor $\mathrm{Sn}$ exposure by means of urinalysis for Sn (i.e., Sn-U) were unsuccessful (Table 3). The details of the toxico-kinetics for inorganic Sn $[4,5]$ remain yet to be investigated. It was considered to be likely $[4,5]$ that less than $5 \%$ of Sn-D will be absorbed through the gastro-intestinal tract, that a majority will be discharged in feces, and that Sn absorbed will be deposited mostly in bones. Urine was considered to be the main route of excretion for absorbed $\mathrm{Sn}$ in addition to bile [4]. Nevertheless, urinary excretion was reported to be quite show with half-lives of 4, 25 and 400 days, accounting for 20, 20 and $60 \%$ of the excretion, respectively [5]. Thus, it would be too optimistic to expect a quantitative relation between Sn-D and Sn-U.

Recently, a variety of packing materials are available other than tin-plated cans, for example., plastics- or paperpack for preservation of foods. Thus, this study may indicate the Sn-D intake substantially higher than the current level. A follow-up study on both children and adult people is apparently desirable.

Acknowledgments The authors are grateful to the participating children and their guardians, and administrations and staff of the kindergartens for their participation in the study. This work was supported in part by Grants from the Ministry of Education, Culture, Sports, Science and Technology, Japan: Grant-in-Aid for Scientific Research C: 22500755 (Head Investigator; T. Watanabe for fiscal years 2010-2012), and Grant-in-Aid for Scientific Research C; 
26350150 (Head Investigator; H. Nakatsuka for fiscal years 2014-2016).

Conflict of interests The authors declare that they have no conflicts of interest.

\section{References}

1. Blunden S, Wallace T. Tin in canned food; a review and understanding of occurrence and effect. Food Chem Toxicol. 2003;41:1651-2.

2. Shimbo S, Matsuda-Inoguchi N, Watanabe T, Sakurai K, Date C, Nishimura A, et al. ietary intake of tin in Japan, and the effects on intake of canned food and beverage consumption. Food Addit Contam. 2007;24:535-45.

3. Shimbo S, Watanabe T, Nakatsuka H, Yaginuma-Sakurai K, Ikeda M. Dietary tin intake and association with canned food consumption in Japanese preschool children. Environ Health Prev Med. 2013;18:230-6.

4. International Programme on Chemical Safety. Environmental health criteria 15. Tin and organotin compounds: 1.4 Metabolism. Geneva: World Health Organization; 1980, pp. 19-20.

5. World Health Organization (WHO) Concise International Assessment Document. No. 65. Tin and inorganic tin compounds: 7. Comparative kinetics and metabolism in laboratory animals and humans. Geneva: World Health Organization; 2005. pp. 17-21.

6. Nakatsuka H, Ko Y, Yang H-R, Monn C-S, Watanabe T, Kin E-S, et al. Food intake survey of kindergarten children in Korea: part 1. Food, energy, and nutrient intake. Environ Health Prev Med (in press).

7. Japan Society for Analytical Chemistry, editor. Analysis and reliability of the analysis results. Tokyo: Maruzen; 1998. p. 52 (in Japanese).

8. World Health Organization (WHO). Guideline for the study of dietary of chemical contaminants. WHO Offset Publication No. 87. Geneva: WHO.

9. Kassouf A, Chebib H, Lebbos V, Ouaini R. Migration of iron, lead, cadmium and tin from tinplate-coated cans into chickpeas. Food Addit Contam Part A Chem Control Expo Risk Assess. 2013;30:1987-92.

10. Olmedo P, Pla A, Hernández AF, Barbier F, Ayouni L, Gil F. Determination of toxic elements (mercury, cadmium, lead, tin and arsenic) in fish and shellfish samples. Risk assessment for consumers. Environ Int. 2013;59:63-72.

11. Bautakhrit K, Crisci M, Bolle F, Van Loco J. Comparison of hour analytical techniques based on atomic spectrometry for the determination of total tin in canned foodstuffs. Food Addit Contam Part A Chem Control Expo Risk Assess. 2011;28:173-9.

12. Acheson KJ, Campbell IT, Edholm OG, Miller DS, Stock MJ. The measurement of food and energy intake in man-an evaluation of some techniques. Am J Clin Nutr. 1980;33:1147-54.

13. Nakatsuka H, Shimbo S, Watanabe T, Yaginuma-Sakurai K, Ikeda M. Applicability of food composition tables as a tool to estimate mineral intake of preschool children in Japan: a validation study. J Trace Elem Med Biol. 2013;27:339-45. 